\title{
Toxicidade da ricina presente nas sementes de mamona
}

\author{
Toxicity of ricin present in castor bean seeds
}

\author{
Nayanna Brunna da Silva Fonseca ${ }^{1}$; Benito Soto-Blanco ${ }^{2 *}$
}

\section{Resumo}

A mamona (Ricinus communis) é um arbusto da família Euforbiacea cultivada para a obtenção do óleo das sementes. Este óleo apresenta amplo emprego industrial, com destaque para o biodiesel. No entanto, as sementes de mamona apresentam uma potente toxina, a ricina. Trata-se de uma glicoproteína altamente tóxica com ação inativadora de ribossomos. A ação tóxica da ricina é decorrente da inibição da síntese proteica nas células eucarióticas, ocasionando a morte celular. Apenas uma molécula de ricina que entra no citosol é capaz de inativar mais de 1500 ribossomos por minuto. Os sinais clínicos associados com a intoxicação de mamona em animais frequentemente ocorrem em algumas horas após a ingestão das sementes. Este trabalho faz uma revisão da literatura sobre os efeitos tóxicos da ricina e as técnicas para a prevenção da intoxicação.

Palavras-chave: Ricinus communis, Euforbiacea, toxalbumina, planta tóxica, toxina

\begin{abstract}
The castor bean (Ricinus communis) is a bush from Euphorbiacea family cultivated for obtaining oil from the seeds. This oil has broad industrial employment, particularly for biodiesel. However, castor bean seeds exhibit a potent toxin, ricin. It is a glycoprotein with highly toxic action of inactivating ribosomes. The toxic action of ricin is due to inhibition of protein synthesis in eukaryotic cells, causing cell death. Only one molecule of ricin that enters the cytosol is able to inactivate ribosomes over 1500 per minute. Clinical signs associated with castor bean poisoning often occur in animals in a few hours after ingestion of the seeds. This paper reviews the literature on the toxic effects of ricin and techniques for preventing the poisoning.
\end{abstract}

Key words: Ricinus communis, Euforbiacea, toxalbumin, poisonous plant, toxin

${ }^{1}$ Discente de Doutorado do Programa de Pós-graduação em Ciência Animal, Universidade Federal Rural do Semiárido, UFERSA, Mossoró, RN. E-mail: nayanna_brunna@yahoo.com.br

${ }^{2}$ Prof. Dr. do Dept $^{\circ}$ de Clínica e Cirurgia Veterinárias, Universidade Federal de Minas Gerais, UFMG, Belo Horizonte, MG. E-mail: benito.blanco@pq.cnpq.br

* Autor para correspondência 


\section{Introdução}

Ricinus communis é um arbusto da família Euforbiacea, oriundo da Etiópia e gradativamente disseminado para a África do Sul, região do Mediterrâneo e regiões mais quentes da Ásia (GARCIA-GONZALEZ et al., 1999). Há relatos de sua utilização desde a antiguidade na Medicina Grega e Egípcia Clássica (OLSNES, 2004; CANGEMI; SANTOS; CLARO NETO, 2010), com descrição no texto médico Susruta Ayurveda, escrito em sânscrito no século VI a.C. (OLSNES, 2004).

Conhecida popularmente como mamona ou carrapateira, é cultivada em toda zona tropical e subtropical do mundo. Possui fácil cultivo, resistência à seca e boa adaptação a diferentes condições edafoclimáticas. É tolerante a uma ampla faixa de temperatura, sendo, muitas vezes, cultivada como planta ornamental em zonas temperadas, apesar de crescer melhor em temperaturas elevadas (OLIVEIRA et al., 2005).

A mamoneira é um arbusto com altura por volta de 2,5 metros, mas pode alcançar 12 metros. Suas folhas são grandes, com coloração verdeavermelhada, podendo variar a tonalidade, possui entre 15 e $30 \mathrm{~cm}$ de largura, formato de palma com 5 a 11 lóbulos serrados (OLIVEIRA; GIMMENEZ; GODOY, 2007; FRIEDMAN et al., 2010). Possui na mesma inflorescência flores masculinas (amarelas), localizadas na porção inferior da inflorescência e flores femininas (vermelhas), situadas na porção superior da inflorescência (OLIVEIRA; GIMMENEZ; GODOY, 2007; FRIEDMAN et al., 2010). Os frutos são cápsulas espinhosas, cujo diâmetro varia de $1,27 \mathrm{~cm}$ a 2,54 cm e a coloração se transforma de amarelo para azul-esverdeado e, posteriormente, para marrom à medida que amadurece. Cada cápsula possui 3 casas contendo sementes tóxicas que se assemelham a carrapatos (FRIEDMAN et al., 2010). Estas sementes são lisas, pretas com manchas brancas (OLIVEIRA; GIMMENEZ; GODOY, 2007).

\section{Produtos da Mamona}

A partir das sementes de Ricinus communis se extrai o óleo de rícino, o qual representa, em média, cerca de 46 a 55\% em peso de cada semente (OGUNNIYI, 2006), podendo chegar a 60\% (COOK; DAVID; GRIFFITHS, 2006). A extração inicial é feita por preensagem mecânica, removendo apenas cerca de $45 \%$ do óleo presente nas sementes, e a obtenção do restante de óleo ocorre por meio de solventes como hexano, heptano, éteres de petróleo (OGUNNIYI, 2006). O óleo obtido não contém a toxina ricina, pois a proteína da semente permanece no subproduto da extração (MAIA et al., 2010).

É um óleo altamente viscoso, de cor amareloclaro, não volátil, não comestível, formado principalmente de ácido ricinoléico (mais de 90\%) e pequenas quantidades de outros ácidos, como: oléico, linoléico, esteárico e dihidroxiesteárico (OGUNNIYI, 2006). Há séculos este óleo vem sendo utilizado por suas propriedades lubrificante e laxante (DOAN, 2004), além de diversos outros usos, como matéria-prima na fabricação de detergentes, cosméticos, produtos farmacêuticos (GOWDA et al., 2008), tais como compostos antifúngicos e lubrificantes espermicidas; próteses (CANGEMI; SANTOS; CLARO NETO, 2010); revestimento de tecido, tintas, vernizes, ceras, giz de cera, pomadas (FRIEDMAN et al., 2010); e produção de biodiesel (VISSER et al., 2011). A produção do biodiesel a partir da mamona está inserida no Programa Nacional de Produção e Uso de Biodiesel (PNPB), que visa estimular a produção do biodiesel no país, além de incentivar pequenos produtores, propiciando a geração de emprego e renda no campo, de maneira sustentável, econômica e social (CÉSAR; BATALHA, 2011).

A obtenção do óleo de mamona gera resíduos que precisam de aproveitamento econômico e ecologicamente viável (SILVA et al., 2010). Dentre os subprodutos obtidos após a extração tem-se a torta, o farelo (BONFIM; SILVA; SANTOS, 2009; SILVA et al., 2010), a casca de mamona (LIMA et 
al., 2008; BONFIM; SILVA; SANTOS, 2009) e a glicerina (SILVA et al., 2010).

A torta de mamona, obtida a partir da extração física do óleo (prensagem) (BONFIM; SILVA; SANTOS, 2009), é o principal resíduo da cadeia produtiva da mamona, muito utilizada em todo o mundo como adubo orgânico (ZUCHI et al., 2007). Este adubo é uma ótima fonte de nitrogênio, fósforo, cálcio e potássio, principalmente, quando comparada a outros adubos orgânicos, como o esterco bovino (CANGEMI; SANTOS; CLARO NETO, 2010). Possui ainda possível efeito nematicida controlando o desenvolvimento de nematoides no solo (LORDELLO; SABINO, 1985; CANGEMI; SANTOS; CLARO NETO, 2010). Além disso, possui alto valor proteico, cerca de 34 a 36\% (MADEIRA-JÚNIOR; MACEDO; MACEDO, 2011), e poderia ser utilizada como substituto de fontes protéicas tradicionais na alimentação animal, porém a presença de fatores tóxicos não permite este uso sem que antes seja feito a detoxificação (ANANDAN et al., 2005).

\section{Características da Ricina}

A ricina é uma toxalbumina, glicoproteína altamente tóxica, presente nas sementes de $R$. communis (ALEXANDER et al., 2008), que representa cerca de $2 \%$ do peso total de uma semente (COOK; DAVID; GRIFFITHS, 2006). É um pó branco na sua forma pura (MUSSHOFF; MADEA, 2009), solúvel em água (ALEXANDER et al., 2008; MUSSHOFF; MADEA, 2009), estável em temperatura ambiente, mas termolábil (GARLAND; BAILEY, 2006). Encontra-se em maior quantidade no endosperma das sementes, que é o local onde é sintetizada, e em menor quantidade nas outras partes da planta (ALEXANDER et al., 2008). Sua função biológica é servir como uma proteína de armazenamento, além da sua potente toxicidade impedir a predação (LORD; SPOONER, 2011).

A ricina é uma toxina classificada como proteína inativadora de ribossomos (RIPs). Existem dois tipos de RIPs, que variam com base na sua estrutura, a do tipo 1 monomérica e a do tipo 2 dimérica (COOK; DAVID; GRIFFITHS, 2006). A ricina é heterodimérica e possui uma cadeia A (peso molecular de $32 \mathrm{kDa}$ ), enzima inativadora de ribossomos, ligada por uma ponte dissulfeto a uma cadeia B (peso molecular de 34kDa) (LORD; ROBERTS; ROBERTUS, 1994; MUSSHOFF; MADEA, 2009). A cadeia A é responsável pela inibição da síntese proteica nas células eucarióticas, enquanto que a cadeia B é uma lectina, inativa cataliticamente, mas que serve para permitir a entrada do complexo proteico AB para o citosol (MUSSHOFF; MADEA, 2009).

A cadeia B se liga a glicoproteínas e glicolipídeos contendo galactosídeos na superfície celular, permitindo a internalização da toxina, através de endocitose (ALBRETSEN; GWALTNEY-BRANT; KAHN, 2000). A absorção endocítica de ricina é muito lenta(cerca de $10 \%$ de ricina por hora a $37^{\circ} \mathrm{C}$ ), quando comparada a outras moléculas que sofrem endocitose (DOAN, 2004). Provavelmente seja este o motivo do período de latência 8 a 24horas, observado entre a ingestão da toxina e o surgimento dos primeiros sinais clínicos (GARLAND; BAILEY, 2006).

Para que a cadeia A possa exercer sua ação, é necessário que a toxina internalizada seja encaminhada para o citoplasma da célula. Sendo assim, após a endocitose, a ricina poderá assumir três caminhos: (1) pode se separar do endossomo e ser encaminhada para os lissossomos, onde será degradada; (2) ainda unida aos seus locais de ligação, pode ser reciclada para a superfície celular através de estruturas tubulares e vesiculares que se originam da membrana do endossomo; ou (3) pode ser transportada para o Complexo de Golgi, onde será transportada de forma retrógrada para o retículo endoplasmático rugoso (DOAN, 2004). A separação das cadeias A e B é feita pela dissulfeto isomerase no lúmen do retículo endoplasmático (LORD; SPOONER, 2011). Posteriormente, a cadeia $\mathrm{A}$, promove a remoção de uma adenina 
específica (depurinação) da porção $28 \mathrm{~S}$ do ácido ribonucléico (RNA) ribossomal contido na subunidade 60S. Desta forma, não ocorre o alongamento da cadeia de polipeptídeos (OLSNES, 2004), ou seja, a síntese proteica é bruscamente inibida (ALBRETSEN; GWALTNEY-BRANT; KAHN, 2000). Apenas uma molécula de ricina que entra no citosol é capaz de inativar mais de 1500 ribossomos por minuto, ocasionando a morte celular(MUSSHOFF; MADEA, 2009). Estudos in vivo e in vitro tem demonstrado que a atividade citotóxica da ricina ocorre não apenas por inibição da síntese proteica, mas também por estresse oxidativo, gerando grandes quantidades de espécies reativas de oxigênio, resultando em morte celular (SUNTRES; STONE; SMITH, 2005).

\section{Toxicidade da Ricina}

A intoxicação pela ricina presente nas sementes de mamona já foi identificada em grande número de espécies animais e em seres humanos (SOTOBLANCO et al., 2002; GARLAND; BAILEY, 2006; ALEXANDER et al., 2008). Há uma importante variação na susceptibilidade à intoxicação entre as espécies animais; os equinos são os animais mais suscetíveis à intoxicação, ovinos, bovinos e suínos são intermediários, enquanto as galinhas são as mais resistentes (GARLAND; BAILEY, 2006; ALEXANDER et al., 2008; TOKARNIA et al., 2012). Cães também são susceptíveis; a intoxicação por ricina em gatos tem sido pouco documentada (BOTHA; PENRITH, 2009). Além da variação entre as espécies animais, a toxicidade de ricina varia de acordo com a via de exposição. A dose letal oral média $\left(\mathrm{DL}_{50}\right)$ em camundongos é de $30 \mathrm{mg} /$ $\mathrm{kg}$, ou aproximadamente 1000 vezes maior do que a a dose reportada para intoxicar por via parenteral ou inalatória (AUDI et al., 2005). Essa menor toxicidade da ricina, por via oral, pode ser devido à sua pobre absorção (ROXAS-DUNCAN; SMITH, 2012) e à sua parcial destruição no lúmen do trato intestinal (OLSNES, 2004; ROXAS-DUNCAN;
SMITH, 2012). A Tabela 1 apresenta as doses letais para diferentes espécies das sementes de Ricinus communis administradas por via oral.

Tabela 1. Dose letal das sementes de Ricinus communis administradas por via oral a diferentes espécies.

\begin{tabular}{lc}
\hline \multicolumn{1}{c}{ Espécie } & Dose letal $(\mathbf{g} / \mathbf{k g})$ \\
\hline Bovinos adultos & 2,0 \\
Bovinos jovens & 0,5 \\
Cães & 1,0 a 2,0 \\
Caprinos adultos & 5,5 \\
Caprinos jovens & 0,5 \\
Coelhos & 0,7 a 1,0 \\
Equinos & 0,1 \\
Galinhas & 14,0 a 14,4 \\
Gansos & 0,4 \\
Ovinos & 1,25 \\
Patos & 0,7 a 1,2 \\
Suínos adultos & 1,3 a 1,4 \\
Suínos jovens & 2,3 a 2,4 \\
\hline
\end{tabular}

Fonte: BRITO; TOKARNIA, 1997; TOKARNIA et al., 2012; GARLAND; BAILEY, 2006; ALEXANDER et al., 2008; BOTHA; PENRITH, 2009.

Aricina époucoabsorvida no trato gastrointestinal (ALBRETSEN; GWALTNEY-BRANT; KAHN, 2000; GARLAND; BAILEY, 2006) e 24horas após a ingestão, grande parte da toxina é encontrada no intestino grosso. Depois de absorvida é, provavelmente, distribuída em todo o espaço fluido extracelular do corpo (GARLAND; BAILEY, 2006). Os sinais clínicos associados com a intoxicação de mamona em animais frequentemente ocorrem em algumas horas após a ingestão das sementes. Inicialmente, ocorre irritação gastrointestinal com a presença de vômitos, diarreia e dor abdominal. Esta diarreia, frequentemente, progride para uma diarreia sanguinolenta. A ricina pode causar efeitos tóxicos no fígado e rim, causando aumento das enzimas hepáticas e falência renal (ALBRETSEN; GWALTNEY-BRANT; KAHN, 2000); além disso, a ricina também pode ocasionar distúrbios cardíacos devido a interferência na função intracelular, como, 
por exemplo no transporte de cálcio intracelular (MA et al., 1996), causando hipotensão, aumento do débito cardíaco, hemorragia e necrose do miocárdio. Outros sinais que podem ocorrer são desidratação, melena, letargia, convulsões e morte (ALBRETSEN; GWALTNEY-BRANT; KAHN, 2000).

As condições mais comuns para que ocorra a intoxicação em animais pelas sementes de mamona, de maneira geral, são ingestão acidental ou intencional das sementes ou da torta não detoxificada (TOKARNIA et al., 2012). As sementes precisam ser esmagadas ou quebradas para que a toxalbumina seja liberada (ALBRETSEN; GWALTNEYBRANT; KAHN, 2000). Assim, a ingestão da torta pode ser mais perigosa do que a ingestão da própria semente de mamona, já que a ricina está disponível para absorção (HONG et al., 2011).

\section{Intoxicação pela Ricina}

Os sinais mais comuns são vômitos, seguido por depressão, diarreia aquosa que frequentemente evolui para diarreia sanguinolenta, e dor abdominal. Pode ocorrer ainda anorexia, hematêmese, fraqueza, hipertermia, ataxia, sialorreia, decúbito e taquicardia. Outros sinais menos frequentes incluem coma, tremores, convulsões, desidratação, palidez, dispneia, polidipsia ou anúria, melena, icterícia e vocalizações (ALBRETSEN; GWALTNEYBRANT; KAHN, 2000; FERNANDES; BACCARIN; MICHIMA, 2002; SOTO-BLANCO et al., 2002; ASLANI et al., 2007). Normalmente, os sinais se desenvolvem após 6 horas da ingestão, ea duração dos sinais geralmente varia de 1,5 a 5,5 dias (ALBRETSEN; GWALTNEY-BRANT; KAHN, 2000).

Quanto aos achados laboratoriais, a avaliação hematológica de animais intoxicados pode revelar elevação do volume globular, devido à desidratação e hipotensão; o perfil bioquímico sérico pode mostrar aumento das atividades de alanina aminotransferase (ALT) e aspartato aminotransferase (AST) e das concentrações de ureia e creatinina (ASLANI et al., 2007; BOTHA; PENRITH, 2009; HONG et al., 2011).

À necropsia, os achados macroscópicos incluem lesões gastrointestinais com hemorragia, congestão pulmonar e leve edema; petéquias no pericárdio, fígado aumentado de tamanho e congesto, e congestão renal (SOTO-BLANCO et al., 2002; ASLANI et al., 2007; BOTHA; PENRITH, 2009). Na análise histológica podem-se encontrar hemorragia e necrose multi-focal em órgãos linfoides; coração com áreas hemorrágicas e necróticas, podendo haver áreas de depósito de material indeterminado; degeneração de hepatócitos e dilatação dos sinusoides hepáticos; baço com diminuição da polpa vermelha e acúmulo de hemossiderina; rins com degeneração tubular necrótica e glomerulonefrite membranosa; no trato gastrointestinal pode ser observado congestão, hemorragia, células epiteliais das criptas focalmente necróticas e submucosa difusamente hemorrágica (SOTO-BLANCO et al., 2002; ASLANI et al., 2007; BOTHA; PENRITH, 2009; ROELS et al., 2010; HONG et al., 2011).

No período de 1969 a 1971, milhares de patos morreram nos EUA, devido intoxicação por mamona. Os sinais clínicos apresentados eram semelhantes aos do botulismo, exceto os sinais de fezes mucoides, tingidas de sangue. As lesões mais comuns eram alteração gordurosa grave no fígado, petéquias amplamente distribuídas e enterite catarral. Depois do ocorrido, foi realizada a intoxicação experimental, que consistiu da administração forçada de sementes de mamona intactas em patos (Anas platyrhynchos), que indicou uma $\mathrm{DL}_{50}$ entre três e quatro sementes por ave (JENSEN; ALLEN, 1981). A administração de torta de mamona, preparada através de sementes de mamona assadas a temperatura de $140^{\circ} \mathrm{C}$ por 20 minutos e considerada isenta de ricina após análise química, também foi capaz de promover sinais de intoxicação em patos. A torta foi adicionada aos níveis de 0,10 , 15,20 e $25 \%$ da dieta de patos com 6 semanas. Sinais de diarreia, emagrecimento e morte foram 
observados, principalmente, em patos alimentados com níveis mais altos da torta na dieta (20 e $25 \%$ ). $\mathrm{Na}$ necropsia havia congestão dos órgãos e enterite hemorrágica. Nos achados histopatológicos, foram observadas lesões degenerativas nas células do epitélio renal, hepatócitos, proliferação de ductos biliares e depleção linfocitária nos órgãos linfoides. O consumo médio diário de alimentos e ganho de peso diminuiu (OKOYE et al., 1987).

O pólen da mamona também foi tóxico para abelhas em condições controladas de laboratório, porém mais estudos são necessários, sob condições naturais, para ver o real risco que as abelhas Apis mellifera sofrem ao polinizar a Ricinus communis (ASSIS JÚNIOR et al., 2011). Neste caso, o responsável pela intoxicação parece ser o alcaloide ricinina, e não a ricina, mas esta hipótese necessita ser confirmada.

\section{Diagnóstico da Intoxicação por Ricina}

O diagnóstico de intoxicação por ricina é, geralmente, baseado na história clínica de consumo de mamona (BOTHA; PENRITH, 2009), observação de êmese contendo partes da planta, e ocorrência de surto grave de doença gastrointestinal ou respiratória (ROELS et al., 2010). Pode ser feita a identificação de mamona no conteúdo gastrointestinal ou fezes (BOTHA; PENRITH, 2009). A detecção de ricina em sangue e fluidos corpóreos pode ser feita por meio de ensaio imunoenzimático (ELISA) (COOK; DAVID; GRIFFITHS, 2006; ROELS et al., 2010) e radioimunoensaio (ROELS et al., 2010). Acromatografia líquida acoplada a espectrofotometria de massas (CL/EM)pode ser feita em conteúdo gástrico para a detecção do biomarcador ricinina, cujo limite de detecção é de 1,0 $\mathrm{ng} / \mathrm{g}$ (MOUSER et al., 2007). Além disso, a ricinina também poderá ser usada como biomarcador em amostras de urina de humanos e animais expostos a doses letais de ricina. Estudos indicam que 48 horas após exposição à dose letal de ricina, a ricinina é encontrada na urina de ratos, através de CL/EM, utilizando $0,083 \mathrm{ng} / \mathrm{mL}$ como limite de detecção (JOHNSON et al., 2005).

A confirmação de exposição é importante para o diagnóstico de intoxicação por ricina, visto que a ingestão de mamona não é sempre fatal, as lesões histológicas são inespecíficas, e o grau de mastigação pode influenciar a dose de ricina que foi exposta (MOUSER et al., 2007).

\section{Tratamento e Profilaxia da Intoxicação por Ricina}

Não há antídotos disponíveis no mercado para este tipo de intoxicação (GARLAND; BAILEY, 2006; HONG et al., 2011). A maneira mais eficaz de tratamento da intoxicação por ricina seria a aplicação de soro de animais imunizados contra a ricina, porém, na prática isso é inviável (TOKARNIAet al., 2012). O tratamento então é sintomático e de suporte, onde, dependendo da situação é realizada a indução do vômito, administração de carvão ativado, sucralfato, lavagem gástrica; dieta suave (GARLAND; BAILEY, 2006); intensa fluidoterapia intravenosa e terapia eletrolítica (SOTO-BLANCO et al., 2002). Foi verificado experimentalmente que o soro de animais imunizados contra a ricina podem ser utilizados para o tratamento (CLARKE; JACKSON, 1956), no entanto este soro não está disponível comercialmente no Brasil.A utilização de anticorpos monoclonais (PINCUS et al., 2011; REISLER; SMITH, 2012) e o uso de pequenas moléculas inibidoras (Retro-2) de ricina ainda estão em fase de estudo pré-clínico (REISLER; SMITH, 2012).

A administração de doses sub-letais repetidas das sementes de mamona a bovinos resultou na proteção contra doses elevadas (TOKARNIA; DÖBEREINER, 1997), o que provavelmente se deve a produção de anticorpos contra a ricina. Para aumentar a segurança deste procedimento, foi realizada a administração para ratos da ricina inativada pelo calor, mas a utilização 
desta não conferiu proteção aos animais tratados (GONÇALVES; OLORIS; SOTO-BLANCO, 2009).

Como a ricina é uma substância altamente tóxica, com potencial para ser usada como agente de guerra biológica ou de bioterrorismo, muitos trabalhos foram realizados com o intuito de desenvolver mecanismos de proteção contra a intoxicação humana.Assim, algumas vacinas recombinantes contra a ricina foram desenvolvidas (SMALLSHAW et al., 2002, 2005; SMALLSHAW; RICHARDSON; VITETTA, 2007; VITETTA et al., 2006; PORTER et al., 2011). Dentre elas, a RiVax, para a qual dois aminoácidos da proteína ricina foram geneticamente modificados para inativar dois sítios de ação. Com isso, os pesquisadores obtiveram uma proteína mutante, a Y80A V76M ou RiVax, que perdeu a toxicidade, mas manteve a antigenicidade (VITETTA et al., 2006). Outra vacina recombinante é aRVEc, que também está na fase de ensaios em humanos (PORTER et al., 2011; REISLER; SMITH, 2012).

Muitos métodos físicos e químicos foram desenvolvidos para detoxificação da torta de mamona, como exemplo de métodos físicos: imersão (3, 6 e 12 h); ebulição (30 e $60 \mathrm{~min}$ ); vaporização (30 e $60 \mathrm{~min})$; aquecimento $\left(100{ }^{\circ} \mathrm{C}\right.$ por $30 \mathrm{~min}$; $120^{\circ} \mathrm{C}$ por $\left.25 \mathrm{~min}\right)$; e autoclave (15psi por $30 \mathrm{~min}$; 15 psi por $60 \mathrm{~min}$ ). Como exemplo de métodos químicos: aplicação de amônia (7,5 e 12,5 $\mathrm{ml} / \mathrm{kg}$ de torta de ricina); de formaldeído (5 e $10 \mathrm{~g} /$ $\mathrm{kg})$, cal (10, 20 e $40 \mathrm{~g} / \mathrm{kg})$; cloreto de sódio $(5,10$ e $20 \mathrm{~g} / \mathrm{kg}$ ); ácido tânico (5 e $10 \mathrm{~g} / \mathrm{kg}$ ) e hidróxido de sódio $(2,5,5$ e $10 \mathrm{~g} / \mathrm{kg})$. Estes métodos foram avaliados baseando-se na análise quantitativa e qualitativa da ricina, onde de todos estes métodos, a autoclave (15psi por 60min) e o tratamento com cal $(40 \mathrm{~g} / \mathrm{kg})$ foram as técnicas capazes de destruir completamente a ricina, confirmado pela não visualização de bandas correspondente a ricina na eletroforese em gel de poliacrilamida (ANANDAN et al., 2005). Alguns trabalhos não obtiveram o mesmo êxito na detoxificação, por exemplo, Furtado et al. (2012) ao usar autoclave (15psi/60min.) e Oliveira et al. (2010), ao utilizar $40 \mathrm{~g}$ de hidróxido de cálcio $\left(\mathrm{CaOH}_{2}\right)$ por kg de torta de mamona não conseguiram obter $100 \%$ de detoxificação da torta. Os autores relatam que esta diferença na eficácia de detoxificação, provavelmente aconteceu devido aos diferentes teores de ricina entre as variedades genéticas de mamoneira.

Além destes métodos, estudos utilizando métodos biológicos de desintoxificação, através da fermentação de fungos, têm sido realizados para que se torne possível o aproveitamento dos subprodutos de mamona na alimentação animal. Estes fungos, provavelmente, usam a ricina como uma fonte de nutrientes, causando uma redução do seu teor a níveis não detectáveis (GODOY et al., 2009; MADEIRAJÚNIOR; MACEDO; MACEDO, 2011).

Desta forma, mesmo que a detoxificação da torta de mamona por meios físicos, químicos (ANANDAN et al., 2005) e biológicos (GODOY et al., 2009) venha sendo promissora na redução de ricina, muitos estudos ainda são necessários para que haja o uso seguro e economicamente viável dos subprodutos da mamona na alimentação animal.

\section{Considerações Finais}

A produçãoo de biodiesel no Brasil pode resultar em grande aumento na produção das sementes de mamona. Em razão disto, pode haver maior possibilidade de exposição dos animais à̀ planta, tanto diretamente quanto indiretamente por meio dos subprodutos da obtenção do óleo, resultando na intoxicação. Por meio do conhecimento das características da ricina, é possível a adoção de medidas visando a prevenção das intoxicações.

\section{Referências}

ALBRETSEN, J. C.; GWALTNEY-BRANT, S. M.; KAHN, S. A. Evaluation of castor bean toxicosis in dogs: 98 cases. Journal of the American Animal Hospital Association, Lakewood, v. 36, n. 3, p. 229-233, 2000. 
ALEXANDER, J.; ANDERSSON, H. C.; BERNHOFT, A.; BRIMER, L.; COTTRILL, B.; FINK-GREMMELS, J.; JAROSZEWSKI, J.; SOERENSEN, H. Ricin (from Ricinus communis) as undesirable substances in animal feed: scientific opinion of the panel on contaminants in the food chain. European Food Safety Authority (EFSA) Journal, Parma, v. 726, p. 1-38, 2008.

ANANDAN, S.; ANIL-KUMAR, G. K.; GHOSH, J.; RAMACHANDRA, K. S. Effect of different physical and chemical treatments on detoxification of ricin in castor cake. Animal Feed Science and Technology, Amsterdam, v. 120, n. 1, p. 159-168, 2005.

ASLANI, M. R.; MALEKI, M.; MOHRI, M.; SHARIFI, K.; NAJJAR-NEZHAD, V.; AFSHARI, E. Castor bean (Ricinus communis) toxicosis in a sheep flock. Toxicon, Oxford, v. 49, n. 3, p. 400-406, 2007.

ASSIS JÚNIOR, E. M.; FERNANDES, I. M. S.; SANTOS, C. S.; MESQUITA, L. X.; PEREIRA, R. A.; MARACAJÁ, P. B.; SOTO-BLANCO, B. Toxicity of castor bean (Ricinus communis) pollen to honey bees. Agriculture, Ecosystems \& Environment, Amsterdam, v. 141, n. 1-2, p. 221-223, 2011.

AUDI, J.; BELSON, M.; PATEL, M.; SCHIER, J.; OSTERLOH, J. Ricin poisoning: a comprehensive review. Journal of the American Medical Association, Chicago, v. 294, n. 18, p. 2342-2351, 2005.

BONFIM, M. A. D.; SILVA, M. M. C.; SANTOS, S. F. Potencialidades da utilização de subprodutos da indústria de biodiesel na alimentação de caprinos e ovinos. Tecnologia \& Ciência Agropecuária, São Vicente da Serra, v. 3, n. 4, p. 15-26, 2009.

BOTHA, C. J.; PENRITH, M. L. Potential plant poisonings in dogs and cats in southern Africa. Journal of the South African Veterinary Association, Pretoria, v. 80, n. 2, p. 63-74, 2009.

BRITO, M. F.; TOKARNIA, C. H. Intoxicação experimental pelas sementes trituradas de Ricinus communis (Euphorbiaceae) em coelhos. Pesquisa Veterinária Brasileira, Seropédica, v. 17, n. 1, p. 1-7, 1997.

CANGEMI, J. M.; SANTOS, A. M.; CLARO NETO, S. A. Revolução verde da mamona. Química Nova na Escola, São Paulo, v. 32, n. 1, p. 3-8, 2010.

CÉSAR, A. S.; BATALHA, M. O. Análise dos direcionadores de competitividade sobre a cadeia produtiva de biodiesel: o caso da mamona. Produção, São Paulo, v. 21, n. 3, p. 484-497, 2011.

CLARKE, E. G. C.; JACKSON, J. H. The use of immune serum in the treatment of ricin poisoning. British Veterinary Journal, London, v. 112, n. 1, p. 57-62, 1956.
COOK, D. L.; DAVID, J.; GRIFFITHS, G. D. Retrospective identification of ricin in animal tissues following administration by pulmonary and oral routes. Toxicology, Amsterdam, v. 223, n. 1-2, p. 61-70, 2006.

DOAN, L. G. Ricin: mechanism of toxicity, clinical manifestations, and vaccine development. A review. Journal of Toxicology. Clinical Toxicology, New York, v. 2, n. 2, p. 201-208, 2004.

FERNANDES, W. R.; BACCARIN, R. Y.A.; MICHIMA, L. E. S. Intoxicação em eqüino por Ricinus communis: relato de caso. Revista Brasileira de Saúde e Produção Animal, Salvador, v. 3, n. 1, p. 26-31, 2002.

FRIEDMAN, M. H.; ANDREU, M. G.; QUINTANA, H. V.; MCKENZIE, M. Ricinus communis, castor bean. Institute of Food and Agricultural Sciences, Gainesville, n. 244, p. 1-3, 2010. Disponível em: <http://edis.ifas. ufl.edu/pdffiles/FR/FR30600.pdf $>$. Acesso em: 8 maio 2013.

FURTADO, R. N.; CARNEIRO, M. S. S.; CÂNDIDO, M. J. D.; GOMES, F. H. T.; PEREIRA, E. S.; POMPEU, R. C. F. F.; SOMBRA, W. A. Valor nutritivo de dietas contendo torta de mamona submetida a métodos alternativos de destoxificação para ovinos. Arquivo Brasileiro de Medicina Veterinária e Zootecnia, Belo Horizonte, v. 64, n. 1, p. 155-162, 2012.

GARCIA-GONZALEZ, J. J.; BARTOLOMÉ-ZAVALA, B.; DEL MAR TRIGO-PÉREZ, M.; BARCELÓMUÑOZ， J. M.; FERNÁNDEZ-MELÉNDEZ， S.; NEGRO-CARRASCO, M. A.; CARMONA-BUENO, M. J.; VEGA-CHICOTE, J. M.; MUÑOZ-ROMÁN, C.; PALACIOS-PELÁEZ, R.; CABEZUDO-ARTERO, B.; MARTÍNEZ-QUESADA, J. Pollinosis to Ricinus communis (castor bean): an aerobiological, clinical and immunochemical study. Clinical and Experimental Allergy, Oxford, v. 29, n. 9, p. 1265-1275, 1999.

GARLAND, T.; BAILEY, E. M. Toxins of concern to animals and people. Revue Scientifique et Technique Office International of Epizootics, Paris, v. 25, n. 1, p. 341-351, 2006.

GODOY, M. G.; GUTARRA, M. L. E.; MACIEL, F. M.; FELIX, S. P.; BEVILAQUA, J. V.; MACHADO, O. L. T.; FREIRE, D. M. G. Use of a low-cost methodology for biodetoxification of castor bean waste and lipase production. Enzyme and Microbial Technology, Amsterdam, v. 44, n. 5, p. 317-322, 2009.

GONÇALVES, C. A. V.; OLORIS, S. C. S.; SOTOBLANCO, B. Avaliação da capacidade da ricina inativada pelo calor para prevenção da intoxicação pela mamona (Ricinus communis). Acta Veterinaria Brasilica, Mossoró, v. 3, n. 2, p. 84-87, 2009. 
GOWDA, N. K. S.; PAL, D. T.; BELLUR, S. R.; BHARADWAJ, U.; SRIDHAR, M.; SATYANARAYANA, M. L.; PRASAD, C. S.; RAMACHANDRA, K. S.; SAMPATH, K. T. Evaluation of castor (Ricinus communis) seed cake in the total mixed ration for sheep. Journal of the Science of Food and Agriculture, Chichester, v. 89, n. 2, p. 216-220, 2008.

HONG, I. H.; KWON, T. E.; LEE, S. K.; PARK, J. K.; KI, M. R.; PARK, S. I.; JEONG, K. S. Fetal death of dogs after the ingestion of a soil conditioner. Experimental and Toxicologic Pathology, Jena, v. 63, n. 1-2, p. 113117, 2011.

JENSEN, W. I.; ALLEN, J. P. Naturally occurring and experimentally induced castor bean (Ricinus communis) poisoning in ducks. Avian Diseases, Ithaca, v. 25, n. 1, p. 184-194, 1981.

JOHNSON, R. C.; LEMIRE, S. W.; WOOLFITT, A. R.; OSPINA, M.; PRESTON, K. P.; OLSON, C. T.; BARR, J. R. Quantification of ricinine in rat and human urine: a biomarker for ricin exposure. Journal of Analytical Toxicology, Oxford, v. 29, n. 3, p. 149-155, 2005.

LIMA, R. L. S.; SEVERINO, L. S.; ALBUQUERQUE, R. C.; BELTRÃO, N. E. M.; SAMPAIO, L. R. Casca e torta de mamona avaliados em vasos como fertilizantes orgânicos. Revista Caatinga, Mossoró, v. 21, n. 5, p. 102106, 2008.

LORD, J. M.; ROBERTS, L. M.; ROBERTUS, J. D. Ricin: structure, mode of action, and some current applications. FASEB Journal, Bethesda, v. 8, n. 2, p. 201208, 1994.

LORD, J. M.; SPOONER, R. A. Ricin trafficking in plant and mammalian cells. Toxins, Basel, v. 3, n. 7, p. 787801, 2011.

LORDELLO, R. R. A.; SABINO, N. P. Efeito do controle de nematóides na qualidade da fibra do algodoeiro. Bragantia, Campinas, v. 44, n. 2, p. 695-699, 1985.

MA, L.; HSU, C. H.; PATTERSON, E.; THADANI, U.; ROBINSON, C. Ricin depresses cardiac function in the rabbit heart. Toxicology and Applied Pharmacology, New York, v. 138, n. 1, p. 72-76, 1996.

MADEIRA-JÚNIOR, J. V.; MACEDO, J. A.; MACEDO, G. A. Detoxification of castor bean residues and the simultaneous production of tannase and phytase by solid-state fermentation using Paecilomyces variotii. Bioresource Technology, Barking, v. 102, n. 15, p. 73437348, 2011.

MAIA, M. O.; QUEIROGA, R. C. R. E.; MEDEIROS, A. N.; COSTA, R. G.; BOMFIM, M. A. D.; FERNANDES, M. F. Consumo, digestibilidade de nutrientes e parâmetros sanguíneos de cabras mestiças Moxotó suplementadas com óleos de licuri ou mamona. Ciência Rural, Santa Maria, v. 40, n. 1, p. 149-155, 2010.

MOUSER, P.; FILIGENZI, M. S.; PUSCHNER, B.; JOHNSON, V.; MILLER, M. A.; HOOSER, S. B. Fatal ricin toxicosis in a puppy confirmed by liquid chromatography/mass spectrometry when using ricinine as a marker. Journal of Veterinary Diagnostic Investigation, Thousand Oaks, v. 19, n. 2, p. 216-220, 2007.

MUSSHOFF, F.; MADEA, B. Ricin poisoning and forensic toxicology. Drug Testing Analysis, Chichester, v. 1, n. 4, p. 184-191, 2009.

OGUNNIYI, D. S. Castor oil: a vital industrial raw material. Bioresource Technology, Barking, v. 97, n. 9, p. 1086-1091, 2006.

OKOYE, J. O. A.; ENUNWAONYE, C. A.; OKORIE, A. U.; ANUGWA, F. O. I. Pathological effects of feeding roasted castor bean meal Ricinus communis to chicks. Avian Pathology, Houghton, v. 16, n. 2, p. 283-290, 1987.

OLIVEIRA, A. S.; CAMPOS, J. M. S.; OLIVEIRA, M. R. C.; BRITO, A. F.; VALADARES-FILHO, S. C.; DETMANN, E.; VALADARES, R. F. D.; SOUZA, S. M. Nutrient digestibility, nitrogen metabolism and hepatic function of sheep fed diets containing solvent or expeller castor seed meal treated with calcium hydroxide. Animal Feed Science and Technology, Amsterdam, v. 158, n. 1-2, p. 15-28, 2010.

OLIVEIRA, I. P.; SANTOS, K. J. G.; BELTRÃO, N. E. M.; NEVES, B. P.; ARAÚJO, A. A.; OLIVEIRA, L. C. Potenciais da mamona (Ricinus communis) na região Centro-oeste brasileira. Revista Eletrônica Faculdade Montes Belos, São Luis de Montes Belos, v. 1, n. 2, p. 104-130, 2005.

OLIVEIRA, R. B.; GIMMENEZ, V. M. M.; GODOY, S. A.P. Intoxicações com espécies da família Euphorbiaceae. Revista Brasileira de Biociências, Porto Alegre, v. 5, p. 69-71, 2007. Suplemento 1.

OLSNES, S. The history of ricin, abrin and related toxins. Toxicon, Amsterdam, v. 44, n. 4, p. 361-370, 2004.

PINCUS, S. H.; SMALLSHAW, J. E.; SONG, K.; BERRY, J.; VITETTA, E. S. Passive and active vaccination strategies to prevent ricin poisoning. Toxins, Basel, v. 3, n. 9, p. 1163-1184, 2011.

PORTER, A.; PHILLIPS, G.; SMITH, L.; ERWINCOHEN, R.; TAMMARIELLO, R.; HALE, M.; DASILVA, L. Evaluation of a ricin vaccine candidate (RVEc) for human toxicity using an in vitro vascular leak assay. Toxicon, Amsterdam, v. 58, n. 1, p. 68-75, 2011. 
REISLER, R. B.; SMITH, L. A. The need for continued development of ricin countermeasures. Advances in Preventive Medicine, Cairo, v. 2012, n. 149737, p. 1-4, 2012.

ROELS, S.; COOPMAN, V.; VANHAELEN, P.; CORDONNIER, J. Lethal ricin intoxication in two adult dogs: toxicologic and histopathologic findings. Journal of Veterinary Diagnostic Investigation, Thousand Oaks, v. 22, n. 3, p. 466-468, 2010.

ROXAS-DUNCAN, V. I.; SMITH, L. A. Of beans and beads: ricin and abrin in bioterrorism and biocrime. Journal of Bioterrorism \& Biodefense, Westlake, v. S7, n. 2, p. 1-8, 2012.

SILVA, M. S.; MACEDO, L. C.; SANTOS, J. A. B.; MOREIRA, J. J. S.; NARAIN, N.; SILVA, G. F. Aproveitamento de coprodutos da cadeia produtiva do biodiesel de mamona. Exacta, São Paulo, v. 8, p. 279288, 2010.

SMALLSHAW, J. E.; FIRAN, A.; FULMER, J. R.; RUBACK, S. L.; GHETIE, V.; VITETTA, E. S. A novel recombinant vaccine which protects mice against ricin intoxication. Vaccine, Amsterdam, v. 20, n. 27-28, p. 3422-3427, 2002.

SMALLSHAW, J. E.; RICHARDSON, J. A.; PINCUS, S. H.; SCHINDLER, J.; VITETTA, E. S. Preclinical toxicity and efficacy testing of RiVax, a recombinant protein vaccine against ricin. Vaccine, Amsterdam, v. 23, n. 39, p. 4775-4784, 2005.

SMALLSHAW, J. E.; RICHARDSON, J. A.; VITETTA, E. S. RiVax, a recombinant ricin subunit vaccine, protects mice against ricin delivered by gavage or aerosol. Vaccine, Amsterdam, v. 25, n. 42, p. 7459-7469, 2007.
SOTO-BLANCO, B.; SINHORINI, I. L.; GORNIAK, S. L.; SCHUMAHER-HENRIQUE, B. Ricinus communis cake poisoning in a dog. Veterinary and Human Toxicology, Manhattan, v. 44, n. 3, p. 155-156, 2002.

SUNTRES, Z. E.; STONE, W. L.; SMITH, M. G. Ricin-induced tissue toxicity: the role of oxidative stress. Journal of Medical Chemical, Biological and Radiological Defense, Kaneohe, v. 3, n. 301, n. 1205, p. 1-21, 2005.

TOKARNIA, C. H.; BRITO, M. F.; BARBOSA, J. D.; PEIXOTO, P. V.; DÖBEREINER, J. Plantas tóxicas do brasil para animais de produção. 2. ed. Rio de Janeiro: Helianthus, 2012. 566 p.

TOKARNIA, C. H.; DÖBEREINER, J. Sobre a imunidade cruzada entre os princípios tóxicos de Abrus precatorius e Ricinus communis. Pesquisa Veterinária Brasileira, Seropédica, v. 17, n. 1, p. 25-35, 1997.

VISSER, E. M.; OLIVEIRA FILHO, D.; MARTINS, M. A.; STEWARD, B. L. Bioethanol production potential from Brazilian biodiesel co-products. Biomass and Bioenergy, Amsterdam, v. 35, n. 1, p. 489-494, 2011.

VITETTA, E. S.; SMALLSHAW, J. E.; COLEMAN, E.; JAFRI, H.; FOSTER, C.; MUNFORD, R.; SCHINDLER, $\mathrm{J}$. A pilot clinical trial of a recombinant ricin vaccine in normal humans. Proceedings of the National Academy of Sciences, Washington, v. 103, n. 7, p. 2268-2273, 2006.

ZUCHI, J.; BEVILHAQUA, G. A. P.; GALHO, A.; MARQUES, R. L. L.; SILVA, S. D. A. Efeito da torta de mamona sobre componentes de rendimento de trigo. Revista Brasileira de Agroecologia, Cruz Alta, v. 2, n. 2, p. 1080-1083, 2007. 